\title{
ANTIMICROBIAL ACTIVITY OF METHANOLIC EXTRACT OF LUDWIGIA PARVIFLORA L. AGAINST STANDARD BACTERIAL STRAINS AND COMPARISON OF ITS ACTIVITY WITH THAT OF STANDARD ANTIBIOTICS
}

\author{
SHIBU GEORGE ${ }^{*}$, MELVIN JOY ${ }^{2}$ \\ ${ }^{1}$ Department of Zoology, St. Aloysius College, (Affiliated to Mahatma Gandhi University, Kottayam, Kerala), Alappuzha, Kerala, India.
} ${ }^{2}$ St. John's Research Institute, Bengaluru, Karnataka, India. Email: shibugeorgepala@gmail.com

Received: 10 December 2018, Revised and Accepted: 19 January 2019

ABSTRACT

Objective: The objective of this study was to evaluate the antimicrobial activity of methanolic extract of Ludwigia parviflora L. using standard bacterial strains and compare its activity with that of standard antibiotics.

Methods: The antibacterial activity and antibiotic susceptibility tests were done by disk diffusion method using MTCC bacterial strains.

Results: The study revealed that the methanolic extract of the whole plant of L. parviflora L. was effective to inhibit the growth of Staphylococcus aureus, Pseudomonas aeruginosa, Klebsiella pneumoniae, and Escherichia coli. Among the tested strains, S. aureus, P. aeruginosa, K. pneumoniae, and E. coli were more susceptible to the methanolic extract of L. parviflora than the commonly using antibiotic tetracycline $30 \mathrm{mcg}$. The activity of methanolic extract was also higher than the activity of gentamicin $10 \mathrm{mcg}$ against the $P$. aeruginosa.

Conclusion: The study concluded that the crude methanolic extract of the whole plant of $L$. parviflora $\mathrm{L}$. is a good source for antibacterial agent against S. aureus, P. aeruginosa, K. pneumoniae, and E. coli. Hence, this plant can be used as a natural alternative to the common antibiotics such as gentamicin and tetracycline against common bacterial infections after validating its pharmacological and toxicological activities.

Keywords: Antimicrobial activity, Ludwigia parviflora, Antibiotics, Methanolic extract, Disk diffusion method, Gentamicin, Tetracycline.

(c) 2019 The Authors. Published by Innovare Academic Sciences Pvt Ltd. This is an open access article under the CC BY license (http://creativecommons. org/licenses/by/4. 0/) DOI: http://dx.doi.org/10.22159/ajpcr.2019.v12i3.30818

\section{INTRODUCTION}

Plants have been used as a source of medicine in traditional or folk medicine from time immemorial due to their magical power to cure diseases [1]. They not only contain nutrients but also chemicals for providing health benefits. Anticancer, antioxidant, anti-inflammatory, antihelminthic, and antimicrobial agents are common in many plants [2]. These chemicals called phytochemicals are the by-products of plant metabolism and are having specific physiological effects in the human body [3,4]. Many research activities are currently undergoing in the world to discover the medicinal activities of such chemicals. Nowadays, researchers have given more attention to discover new antimicrobial drugs of plant origin because most of the available synthetic antibiotics are losing their capacity to inhibit the growth of microorganisms $[5,6]$. This is mainly due to the ability of microorganisms to develop resistance against the continuously using antibiotics $[7,8]$. Therefore, this study is focused to validate the antimicrobial activity of Ludwigia parviflora $\mathrm{L}$. against standard bacterial strains and also to compare its activity with that of standard antibiotics for suggesting a natural alternative to the commonly available antibiotics.

L. parviflora $\mathrm{L}$. belongs to the family Onagraceae. It is commonly known as water primrose. It is commonly seen in wet places, sandy river bed, along streams, rice field, etc. It has been used in traditional medicine to overcome many diseases including fever [9]. Its leaves and roots are also used in the treatment of ulcer, wound healing, etc. [10].

\section{METHODS}

Preparation of plant extract

The whole plants of L. parviflora L. were collected from different geographical areas of Upper Kuttanad, Alappuzha district, Kerala state. A voucher herbarium specimen was prepared and deposited at the Department of Zoology, St. Aloysius College, Edathua, Alappuzha, Kerala, and the authentic identification of the plant material was done by Mr. Bijeshmon P.P, Botanist, Sreedhareeyam Ayurvedic Research and Development Institute, Koothattukulam, Kerala, India. The collected plant sample was washed thoroughly under tap water, dried under sunlight, and powdered using a mixer grinder. Serial extraction of the powder was made by a Soxhlet extractor using solvents such as petroleum ether, acetone, methanol, and distilled water. The Soxhlet extracts were filtered using Whatman No. 1 filter paper and then concentrated. The concentrate was considered as stock and kept in the refrigerator. From the stock, a concentration of $10 \mathrm{mg} /$ disk was prepared and was used for the preliminary antibacterial screening.

\section{Bacterial strains}

Standard MTCC strains purchased from the Institute of Microbial Technology, Chandigarh (IMTECH), India, were used for the study. The strains were as follows:

1. Staphylococcus aureus (MTCC Code 3160)

2. Escherichia coli (MTCC Code 40)

3. Pseudomonas aeruginosa (MTCC Code 4673)

4. Klebsiella pneumoniae (MTCC Code 3040)

\section{Antibiotic disks}

Standard antibiotic disks purchased from HiMedia Laboratories Pvt. Ltd., Mumbai, India, were used for antibiotic sensitivity comparison. The following antibiotics were used for the study.

1. Chloramphenicol (30 mcg)

2. Gentamicin (10 mcg)

3. Penicillin $\mathrm{G}(10 \mathrm{u})$

4. Ciprofloxacin $(5 \mathrm{mcg})$

5. Tetracycline $(30 \mathrm{mcg})$

6. Amikacin (30 mcg). 


\section{CULTURE MEDIA}

The dehydrated Mueller-Hinton Agar medium purchased from HiMedia Laboratories Pvt. Ltd., Mumbai, India, was used. The medium was rehydrated and sterilized in an autoclave and was poured into sterilized Petri dishes and allowed to set. The plates were stored at $4-10^{\circ} \mathrm{C}$ in the refrigerator. Before inoculation, the surface of the petri plates was dried in an incubator.

\section{ANTIBACTERIAL ASSAY BY DISK DIFFUSION METHOD}

The antibacterial activity and antibiotic sensitivity test were done by disk diffusion method as described by Kirby et al., in 1966 [11]. The dried plates were inoculated by the test strains uniformly over the surface using a sterile cotton swab. A sterile 6-mm Whatman No.1 filter paper loaded with appropriate extract was placed on the surface of the inoculum and gently pressed by a sterile forceps. Control disks (made up of each solvent such as petroleum ether, acetone, methanol, and water) were also placed on the surface of inoculum. The plates were incubated at $37^{\circ} \mathrm{C}$ for $16-20 \mathrm{hrs}$. The zone of inhibition of bacterial growth around the disk was measured in millimeters. Tests were repeated 3 times, and the mean values were calculated (mean fractions were avoided) and recorded. In antibiotic sensitivity test, only the methanolic extract was used because the results of preliminary screening showed that all other extracts (petroleum ether, acetone, and aqueous) were insignificant against the tested strains.

\section{RESULTS AND DISCUSSION}

The result of the antibacterial activity of various extracts of L. parviflora against standard strains is given in Table 1 and the antibiotic susceptibility test in Table 2.

Repeated experiments with control disks showed that they did not possess any inhibitory effect. This indicated that the solvent alone is ineffective to produce antibacterial activity. Similarly, the petroleum ether extracts and aqueous extracts were ineffective against the tested strains. This may be because the antibacterial principles of the tested plant may be soluble in organic, polar solvents such as methanol or partially polar solvent such as acetone. An activity with an inhibition zone of $6-10 \mathrm{~mm}$ is considered a lesser activity and has no significance in antibacterial studies. However, an activity between 11 and $15 \mathrm{~mm}$ can be considered as moderate and those of $15 \mathrm{~mm}$ and above as high and powerful. An activity with $15 \mathrm{~mm}$ or above would be taken into consideration for further studies including purification of the active principles.

The acetone extract of $L$. parviflora showed slight activity against all the tested strains (inhibition zone was $<9 \mathrm{~mm}$, not a prominent activity). However, its methanolic extract was very active against $S$. aureus with an inhibition zone of $21-\mathrm{mm}$ diameter. This activity has very much significance in the field of antibacterial studies. However, the activity of the methanolic extract was moderate against $P$. aeruginosa, K. pneumoniae, and E. coli.

On analyzing the effect of standard antibiotics against the tested strains, it is evident that all the tested antibiotics such as chloramphenicol, gentamicin, ciprofloxacin, tetracycline, and amikacin were active against the four tested strains. Nevertheless, none of the bacterial strains could be inhibited by the antibiotic - Penicillin G which indicates that the Penicillin $\mathrm{G}$ is an outdated antibiotic in the field of antibacterial therapy.
Among the active antibiotics, the strength of activity was varying in different bacterial strains. Maximum inhibition against $S$. aureus was given by ciprofloxacin $5 \mathrm{mcg}$ and minimum inhibition by tetracycline $30 \mathrm{mcg}$. On comparing the results of the preliminary screening, it is clear that the crude methanol extract $(10 \mathrm{mg} /$ disc) of the whole plant of L. parviflora (inhibition zone of $21 \mathrm{~mm}$ ) has higher activity than tetracycline $30 \mathrm{mcg}$. Therefore, the methanolic extract of $L$. parviflora can be taken into consideration for a detailed study to suggest them as an alternative to tetracycline $30 \mathrm{mcg}$ against the treatment of disease caused by S. aureus.

Antibiotic activity against the $P$. aeruginosa showed that ciprofloxacin $5 \mathrm{mcg}$ showed the highest activity and minimum by gentamicin $10 \mathrm{mcg}$. However, tetracycline $30 \mathrm{mcg}$ has been totally resisted by the $P$. aeruginosa. When comparing the tested sample, the crude methanolic extract of L. parviflora showed slightly higher activity against $P$. aeruginosa than gentamicin and tetracycline. Therefore, it can be concluded that the methanolic extract of $L$. parviflora $(10 \mathrm{mg} / \mathrm{disc})$ is a good alternative for gentamicin $10 \mathrm{mcg}$ and tetracycline $30 \mathrm{mcg}$ against the treatment of infections caused by P. aeruginosa (Fig. 1).

Chloramphenicol $30 \mathrm{mcg}$ showed the highest activity against K. pneumoniae and least activity by tetracycline $30 \mathrm{mcg}$. However, the methanolic extract (10 mg/disk) of L. parviflora showed increased activity against the K. pneumoniae. Hence, it can be concluded that the crude methanolic extracts of $L$. parviflora are an alternative source for tetracycline $30 \mathrm{mcg}$ against the growth of $K$. pneumoniae.

Highest inhibition against E. coli was shown by ciprofloxacin $5 \mathrm{mcg}$ and least inhibition by tetracycline $30 \mathrm{mcg}$. However, the methanolic extract of L. parviflora $(10 \mathrm{mg} / \mathrm{disc})$ showed more activity than tetracycline $30 \mathrm{mcg}$ against the E. coli. Therefore, the methanolic extracts of L. parviflora can be considered for a detailed study to suggest them as an alternative to tetracycline $30 \mathrm{mcg}$ in the treatment of diseases caused by E. coli.

One report from Selvamuthu et al. showed that its leaves contain some antibacterial activity [12]. The present study also suggests that the methanolic extract of the whole plant of $L$. parviflora possesses powerful antibacterial activity against $S$. aureus, P. aeruginosa, K. pneumoniae, and E. coli. Since the methanolic extract of the whole plant of $L$. parviflora showed promising activity against all the tested bacterial strains, the present study suggests that this plant can be taken into consideration for isolating the active principle to develop a new broad-spectrum antibiotic against the common pathogenic bacteria and would be used as a more powerful alternative to the common antibiotics, tetracycline and gentamicin (Fig. 2).

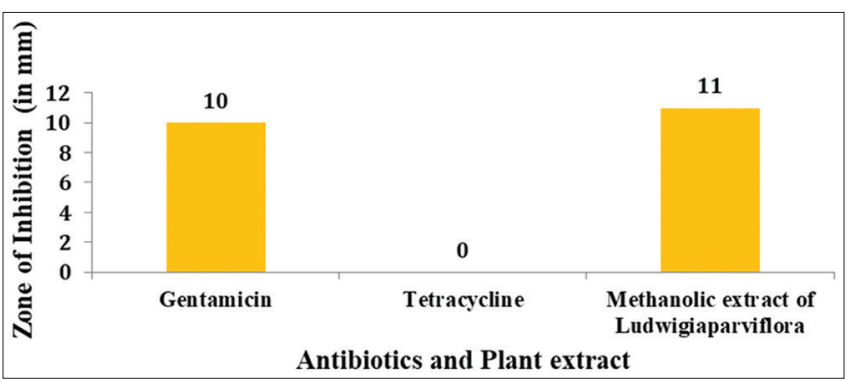

Fig. 1: Activity of methanolic extract of Ludwigia parviflora, tetracycline and gentamicin against Pseudomonas aeruginosa

Table 1: Antibacterial activity of various extracts of $L$. parviflora against standard bacterial strains

\begin{tabular}{|c|c|c|c|c|c|c|c|c|c|c|c|c|c|c|c|c|}
\hline \multirow[t]{3}{*}{ Plant } & \multicolumn{16}{|c|}{ Bacterial strains tested (zone of inhibition in $\mathbf{m m}$ ) } \\
\hline & \multicolumn{4}{|c|}{ Staphylococcus aureus } & \multicolumn{4}{|c|}{ Pseudomonas aeruginosa } & \multicolumn{4}{|c|}{ Klebsiella pneumoniae } & \multicolumn{4}{|c|}{ Escherichia coli } \\
\hline & Pe & A & $\mathbf{M}$ & Aq & $\mathrm{Pe}$ & A & $\mathbf{M}$ & Aq & Pe & A & $\mathbf{M}$ & Aq & $\mathbf{P e}$ & A & $\mathbf{M}$ & Aq \\
\hline L. parviflora & 0 & 8 & 21 & 0 & 0 & 8 & 11 & 0 & 0 & 9 & 11 & 0 & 0 & 7 & 13 & 0 \\
\hline
\end{tabular}

Pe: Petroleum ether extract, A: Acetone extract, M: Methanolic extract, Aq: Aqueous extract, L. parviflora: Ludwigia parviflora 
Table 2: Comparison of the activity of the methanolic extract of $L$. parviflora with that of antibiotics against the standard bacterial strains

\begin{tabular}{lllllllll}
\hline Bacterial strains & \multicolumn{7}{l}{$\begin{array}{l}\text { Standard antibiotics tested } \\
\text { (zone of inhibition in } \mathbf{~ m m ) ~}\end{array}$} \\
\cline { 2 - 8 } & $\mathbf{1}$ & $\mathbf{2}$ & $\mathbf{3}$ & $\mathbf{4}$ & $\mathbf{5}$ & $\mathbf{6}$ & $\mathbf{7}$ \\
\hline Staphylococcus aureus & 25 & 27 & 0 & 35 & 15 & 34 & 21 \\
Pseudomonas aeruginosa & 11 & 10 & 0 & 30 & 0 & 16 & 11 \\
Klebsiella pneumoniae & 22 & 16 & 0 & 24 & 10 & 21 & 11 \\
Escherichia coli & 22 & 20 & 0 & 30 & 11 & 25 & 13 \\
\hline
\end{tabular}

1: Chloramphenicol (30 mcg), 2: Gentamicin (10 mcg), 3: Penicillin G (10 u),

4: Ciprofloxacin ( $5 \mathrm{mcg}$ ), 5: Tetracycline (30 mcg), 6: Amikacin (30 mcg),

7: Methanolic extract of Ludwigia parviflora

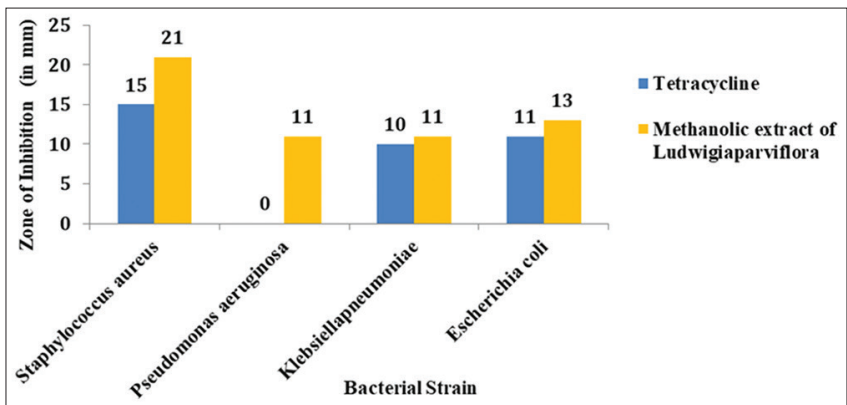

Fig. 2: Activity of methanolic extract of Ludwigia parviflora and tetracycline against standard bacterial strains

\section{CONCLUSION}

The whole plants of L. parviflora collected from various regions of Upper Kuttanad, Alappuzha district, Kerala state, were tested for antibacterial activity against standard MTCC bacterial strains by disk diffusion method. The activity was also compared with the activity of standard antibiotics. The results of the study revealed that the methanolic extract of $L$. parviflora possessed a promising activity against all the tested strains. Its activity was higher than the activity of tetracycline $30 \mathrm{mcg}$ against $S$. aureus, P. aeruginosa, K. pneumoniae, and E. coli. It also showed slightly higher activity than the common antibiotic, gentamicin $10 \mathrm{mcg}$ against the $P$. aeruginosa. Therefore, the study can be concluded that the crude methanolic extract of the whole plant of $L$. parviflora with a concentration of $10 \mathrm{mg}$ /disk is equivalent to gentamicin against $P$. aeruginosa and is also more powerful than tetracycline against all the tested strains. Hence, isolation of active antimicrobial principle from $L$. parviflora and its detailed toxicological and other pharmacological studies are suggesting.

\section{ACKNOWLEDGMENT}

The author is thankful to the University Grants Commission (UGC) for the financial assistance.

\section{AUTHOR'S CONTRIBUTION}

Shibu George was responsible for doing the laboratory work and writing the research paper.

Melvin Joy involved in its result analysis.

\section{CONFLICTS OF INTEREST}

Authors have none to declare.

\section{REFERENCES}

1. Neeraj M, Behal KK. Antimicrobial activity of some spices against selected microbes. Int J Pharm Pharm Sci 2010;2:18796.

2. Hayam MI, Ferial MA. Antibacterial activity of some medicinal plant extracts. Int J Biol Biomol Agric Food Biotechnol Eng 2014;8:1168-73.

3. Bijeshmon PP, Shibu G. Antimicrobial activity and powder microscopy of the flowers of Tabernaemontana divaricata $\mathrm{R}$. Br. Indo Am J Pharm Res 2014;4:1601-5.

4. Rosina K, Barira I, Mohd A, Shazi S, Anis A, Manazir AS, et al. Antimicrobial activity of five herbal extracts against multi drug resistant (MDR) strains of bacteria and fungus of clinical origin. Molecules 2009; 14:586-97.

5. Shibumon G, Benny PJ. Antibacterial potency of fruit extracts of Flacourtia inermis against multidrug resistant strains and comparison of its activity with that of standard antibiotics. Int J Pharm Sci Biotechnol 2010;1:96-9

6. Subhas CM, Harsha R, Dinesha R, Thammanna GS. Antibacterial activity of Coleus aromaticus leaves. Int $\mathrm{J}$ Pharm Pharm Sci 2010;2:63-6

7. Akinyemi KO, Oluwa OK, Omomigbehin EO. Antimicrobial activity of crude extracts of three medicinal plants used in south-west Nigerian folk medicine on some food borne bacterial pathogens. Afr J Trad Complement Alternat Med 2006;3:13-22.

8. Kong JM, Goh NK, Chia LS, Chia TF. Recent advances in traditional plant drugs and orchids. Acta Pharm 2003;24:7-21.

9. Datta SC, Banerjee AK. Useful weeds of West Bengal rice fields. Econ Bot 1979;32:297-310.

10. Mohammad SQ, Venkateshwar R, Kumar GS, Lubna N. Ethnobotanical study on medicinal plants used by traditional health practitioners and villagers of Garhphulghar Gram, Chhattisgarh, India. Asian J Pharm Res 2017;7:98-105.

11. Kirby MD, Bauer AW, Sherris JC, Turck M. Antibiotic susceptibility testing by standardized single disc diffusion method. Am J Clin Pathol 1966:45:493-6.

12. Selvamuthu B, Seetharaman S, Indra V, Daisy A. Antibacterial activity of methanolic extract of Ludwigia perennis leaves. World J Pharm Pharm Sci 2016;5:1186-93. 